\title{
Crioprotetores na criopreservação de sementes de Passiflora mucronata Lam.'
}

\author{
Deizimary Stella de Araújo ${ }^{2}$ (D), Fabiano Silva Soares ${ }^{2}$ (D), \\ Severino de Paiva Sobrinho² (1) \& Petterson Baptista da Luz ${ }^{2}$ (b)
}

\author{
1 Parte da dissertação do primeiro autor, Programa de Pós-graduação em Genética e Melhoramento de Plantas, \\ Universidade do Estado de Mato Grosso, Brasil. \\ 2 Universidade do Estado de Mato Grosso, Departamento de Agronomia, campus Cáceres, \\ Av. Santos Dumont, s/n, CEP 78200-000, Cáceres, MT, Brasil. \\ deizimary@hotmail.com
}

Recebido em 21.IX.2016

Aceito em 14.VI.2019

DOI 10.21826/2446-82312019v74e2019008

RESUMO - O Brasil é um dos centros de diversidade do gênero Passiflora L. e possui um potencial para a utilização dos recursos genéticos na área agronômica. Passiflora mucronata Lam. é uma espécie silvestre com ótimas características para uso ornamental. Este estudo teve por objetivo avaliar o efeito de diferentes concentrações dos crioprotetores: dimetilsulfóxidoe sacarose $(0,7,14,21$ e $28 \%$ ) na criopreservação de sementes de $P$. mucronata. Após a aplicação dos crioprotetores, as sementes foram armazenadas em nitrogênio líquido durante cinco dias, descongeladas, posteriormente semeadas em vermiculita e mantidas em temperatura de $27,7 \pm 1,9^{\circ} \mathrm{C}$. Foram avaliadas as variáveis: emergência, índice de velocidade de emergência, comprimento de parte aérea e raiz e massa seca de plântulas. O tipo de crioprotetor e a aplicação de doses crescentes afetam a qualidade fisiológica de sementes após o armazenamento em nitrogênio líquido. As sementes podem ser armazenadas em nitrogênio líquido sem o uso de crioprotetores.

Palavras-chave: dimetilsulfóxido, maracujá, ornamental, sacarose

\begin{abstract}
Cryoprotector on cryopreservation of Passiflora mucronata Lam. Brazil is one of the centers of diversity of the genus Passiflora L. and therefore has great potential for the utilization of the genetic resources in agronomy. Passiflora mucronata Lam. is a wild species that presents great characteristics for ornamental use. This work aimed to evaluate the effect of different concentrations of cryoprotectants dimethylsulfoxide (DMSO) and sucrose $(0,7,14,21$ and 28\%) on the cryopreservation of Passiflora mucronata seeds. After the application of the cryoprotectants, the seeds were stored in liquid nitrogen for 5 days, thawed, and later, seeded in vermiculite and maintained at a temperature of $27.7 \pm 1.9^{\circ} \mathrm{C}$. The cryoprotectant type and the application of increasing doses affect the physiological quality of seeds after storage in liquid nitrogen. Cryopreservation may be used for the long-term conservation of seeds, without the use of cryoprotectants.
\end{abstract}

Keywords: dimethylsulfoxide, ornamental, passizon fruit, sucrose

\section{INTRODUÇÃO}

Passiflora mucronata Lam., popularmente conhecida como maracujá de restinga ou sururú, é uma espécie silvestre do gênero Passiflora que apresenta porte herbáceo, com características de planta trepadeira e heliófita. Esse maracujazeiro apresenta floração e frutificação durante todo o ano, tornando-a uma excelente espécie para uso ornamental (Cervi 1997, Melleti et al. 2011). A importância das passifloráceas provém da ampla e diversificada utilização pelo homem. Podem ser cultivadas como plantas ornamentais devido à beleza de suas flores e pela variedade de formas de suas folhas (Cruz et al. 2008), entretanto, no Brasil o mercado e cultivo do maracujá como planta ornamental é praticamente inexplorado, apesar do enorme potencial que existe como centro de origem de muitas espécies. Recentemente, com a intensificação da coleta do germoplasma de Passiflora, tem-se dado mais atenção ao comportamento germinativo das sementes e métodos de armazenamento a fim de desenvolver estratégias para sua conservação (Santos et al. 2012).

De acordo com Veiga-Barbosa et al. (2013), a criopreservação de sementes de Passiflora é a opção de armazenamento mais adequada de longo prazo. Por meio desta técnica é possível manter o germoplasma por vários anos sob temperatura ultrabaixa, em geral, $-196^{\circ} \mathrm{C}$ (nitrogênio líquido), devido à redução das atividades metabólicas e dos processos bioquímicos das células. Nesta condição, o risco de perda do material biológico é mínimo, e sendo a criopreservação viável para a espécie, essas podem ter a longevidade das sementes mantida por período indefinido (Engelmann 2011).

Por outro lado, a criopreservação pode provocar danos aos tecidos das sementes por causa da formação de cristais de gelo no interior das células. Desta forma, o conteúdo de água das sementes é o ponto crítico para o desenvolvimento 
de um protocolo de criopreservação, especialmente quando as sementes são intermediárias e recalcitrantes (GonzálezBenito et al. 2009).

Durante a criopreservação, os crioprotetores são fundamentais para sobrevivência das sementes. A utilização dessas substâncias provoca um abaixamento da temperatura de congelamento na qual os cristais de gelo são formados, minimizando e controlando os efeitos deletérios do processo de congelamento e descongelamento (Sakai \& Engelmann 2007). Essas substâncias, conhecidas como agentes crioprotetores (ACPs), são fundamentais para os resultados satisfatórios na criopreservação (Suzuki et al. 2018).

Os crioprotetores mais comumente utilizados em protocolos de criopreservação são dimetilsulfóxido (DMSO), etileno glicol (EG), glicerol e a sacarose. DMSO é um importante agente crioprotetor utilizado em animais, microorganismos e plantas.

O tipo de crioprotetor, a concentração e o tempo de exposição do material podem resultar em efeito tóxico, sendo considerado o maior impedimento da criopreservação pela vitrificação. Há uma redução dependente da dose na sobrevivência de sementes de alface para concentração acima de 20\% de DMSO (Kaurin \& Stushnoff 1985). Outro estudo mostrou o efeito tóxico da utilização de $35 \%$ de DMSO na sobrevivência das sementes, porém com efeito benéfico do DMSO a 15\% (Jaganathan \& Liu 2014). A sacarose é um ótimo agente crioprotetor que não apresenta toxicidade, mesmo quando empregada em altas concentrações (Dumet et al. 1993; Santos 2000). Koleva et al. (2012) revelaram que a sacarose mantém a estrutura do tecido fotossintético em Orthosiphon stamineus. No entanto, ainda não se sabe ao certo como os mecanismos de toxicidade atuam, tornando os testes para a seleção e concentração dos crioprotetores fundamentais para a criopreservação de sementes.

Este trabalho teve por objetivo avaliar o efeito de diferentes concentrações dos crioprotetores dimetilsulfóxido (DMSO) e sacarose na criopreservação de sementes de Passiflora mucronata.

\section{MATERIAL E MÉTODOS}

O experimento foi conduzido no Laboratório de Sementes e Plantas Ornamentais da Universidade do Estado de Mato Grosso. As sementes utilizadas foram provenientes do Banco de Germoplasma de Maracujazeiro da Universidade do Estado de Mato Grosso, Campus de Cáceres. Os frutos foram colhidos maduros e as sementes extraídas manualmente, com remoção da mucilagem pela lavagem em água corrente e cal vigem em peneiras de polietileno. Posteriormente, as sementes foram acondicionadas em recipientes de vidro e armazenadas em refrigerador $\left(7^{\circ} \mathrm{C}\right)$ por sete dias até a instalação dos experimentos.

O grau de umidade das sementes foi determinado pelo método da estufa a $105^{\circ} \mathrm{C}$ por 24 horas (Brasil 2009) com duas repetições de 50 sementes inteiras, após os sete dias de armazenamento segundo recomendação de Araúlo et al. (2016). Os resultados foram calculados com base no peso das sementes úmidas e expressos em porcentagem.

As sementes foram imersas em soluções crioprotetoras (DMSO e sacarose) em diferentes concentrações $(0,7$, 14,21 e $28 \%$ ), por três horas, e em seguida, mantidas sobre bancada de alvenaria, em ambiente de laboratório $\left(27,7^{\circ} \mathrm{C} \pm 1,9\right)$, durante 24 horas, para secagem e adequação da umidade, conforme Cromarty et al. (1985). Para o congelamento, as sementes foram acondicionadas em envelopes aluminizados trifoliados de tamanho $07 \times 11$ $\mathrm{cm}$ e expostas ao nitrogênio líquido, por imersão direta e congelamento rápido, onde permaneceram por 5 dias. $\mathrm{O}$ descongelamento das sementes foi realizado em banhomaria $\left(37^{\circ} \mathrm{C}\right)$ por 5 minutos.

$\mathrm{O}$ teste de emergência foi conduzido sobre bancada de laboratório em caixas "Gerbox" contendo substrato comercial "Vermiculita" na quantidade de 40 gramas. O substrato foi previamente umedecido com água destilada conforme recomendação da Regras para Análise de Sementes (Brasil 2009), sendo o material mantido em ambiente de laboratório $\left(27,7^{\circ} \mathrm{C} \pm 1,9\right)$. O teste teve duração de trinta dias e as contagens foram realizadas diariamente e iniciaram logo após a montagem, obtendose ao final do registro o número de sementes emersas que deram origem a plântulas normais.

Juntamente com o teste de emergência, obteve-se o índice de velocidade de emergência (IVE), de acordo com a fórmula proposta por Maguire (1962). As plântulas foram analisadas quanto ao comprimento médio da parte aérea e da raiz, e massa seca de plântulas inteiras, com auxílio de régua graduada e balança analítica de precisão $(0,01$ g), respectivamente. Os dados de comprimento foram expressos em centímetros e os de massa de plântulas em gramas.

O delineamento experimental utilizado foi o inteiramente casualizado em um arranjo fatorial 2 × 5 ( 2 crioprotetores x 5 concentrações) com quatro repetições de 50 sementes cada uma. Os dados obtidos foram submetidos à análise de variância, pelo programa computacional Sisvar, versão 5.4 (Ferreira 2010) e as médias dos fatores quantitativos analisadas por regressão.

\section{RESULTADOS E DISCUSSÃO}

Neste estudo, para todas as variáveis de qualidade fisiológica de sementes de $P$. mucronata, houve interação significativa $(P<0,01)$ entre o tipo de crioprotetor, DMSO ou sacarose, e as concentrações testadas $(0,7,14,21$, $28 \%$ ). As sementes apresentaram teor de umidade inicial de 7,5\% (base úmida).

A emergência de plântulas diminuiu com o aumento nas concentrações de DMSO e sacarose testadas, apresentando regressão quadrática e linear, respectivamente (Fig. 1A). Inicialmente, os crioprotetores proporcionaram uma diminuição mais lenta na emergência das plântulas. Esta 


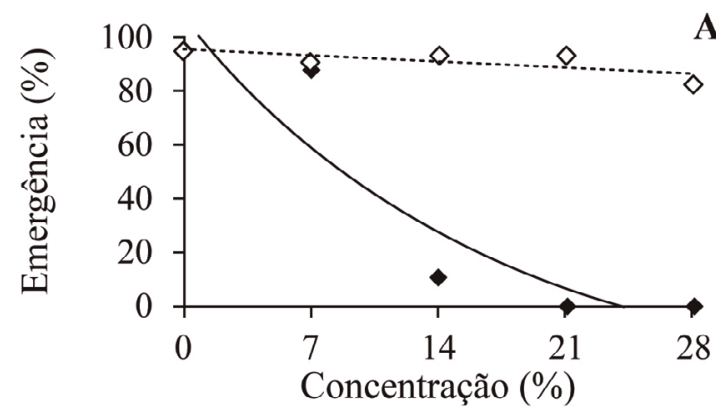

DMSO: $y=105,8286-7,2367 x+0,1166 x^{2} \quad R^{2}=0,87$

SAC: $\quad y=95,6000-0,3286 x \quad R^{2}=0,54$

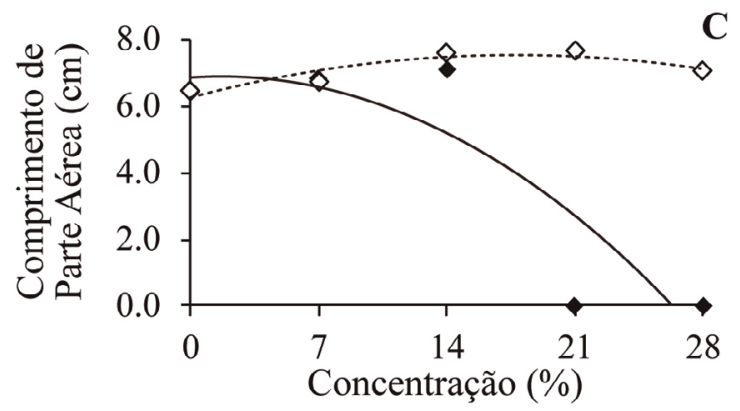

$\rightarrow$ DMSO: $\mathrm{y}=6,8393+0,0546 \mathrm{x}-0,0120 \mathrm{x}^{2} \quad \mathrm{R}^{2}=0,78$

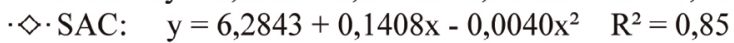

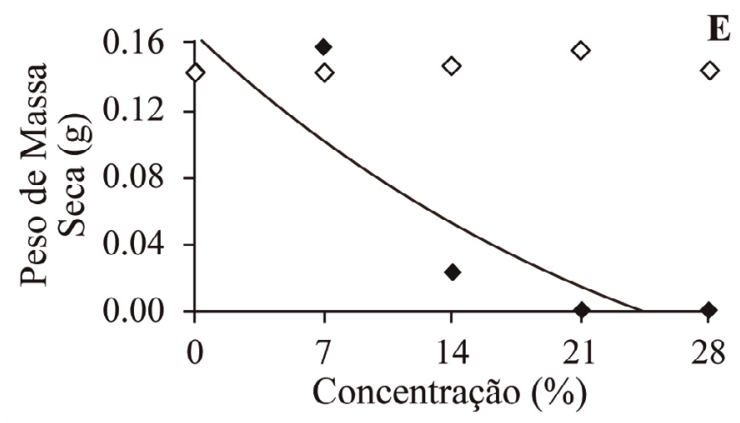

- DMSO: $\mathrm{y}=0,1642-0,0096+0,0001 \mathrm{x}^{2} \quad \mathrm{R}^{2}=0,81$

$\diamond \cdot \mathrm{SAC}: \quad \mathrm{ns}$

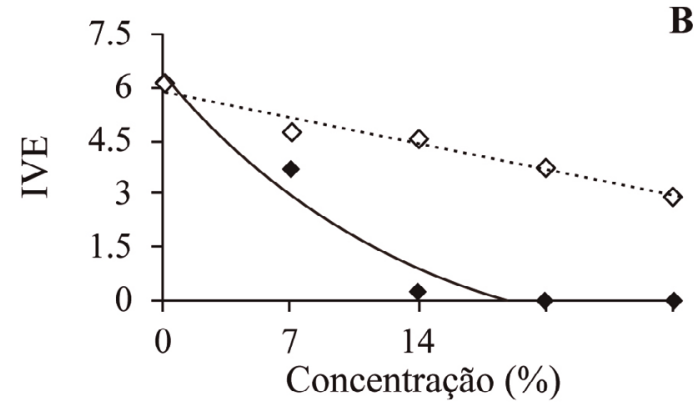

$\rightarrow$ DMSO: $y=6,3627-0,5576 x+0,0228 x^{2} \quad R^{2}=0,97$

$\bullet \diamond \cdot \mathrm{SAC}: \quad \mathrm{y}=5,8975-0,1066 \mathrm{x} \quad \mathrm{R}^{2}=0,96$

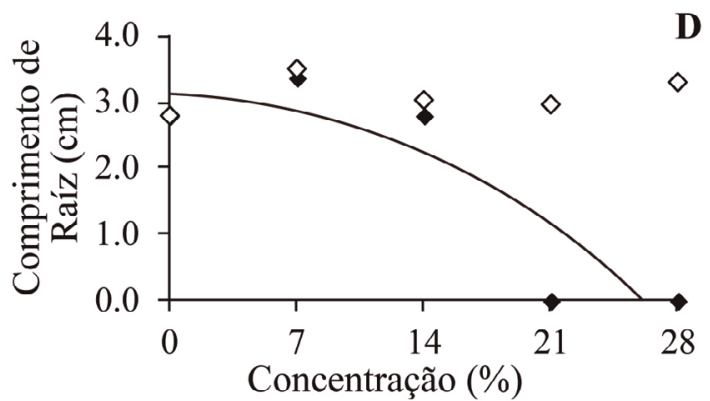

DMSO: $y=3,0789+0,0077 x-0,0048 x^{2} \quad R^{2}=0,81$

SAC: $\mathrm{ns}$

Figs. 1A-E. Efeito da concentração (0, 7, 14, 21 e 28\%) e crioprotetor (sacarose e DMSO) sobre a porcentagem de emergência. A. Porcentagem de emergência; B. Índice de velocidade de emergência; C, D. Comprimento de parte aérea e de radícula; E. Massa seca de plântulas de sementes de Passiflora mucronata aos 30 dias.

diferença acentuou-se em relação ao DMSO, conforme o aumento das concentrações testadas. A maior concentração culminou numa redução de $100 \%$ na emergência das plântulas tratadas com DMSO, e de aproximadamente $13 \%$ nas sementes tratadas com sacarose.

Este resultado permite inferir que concentrações elevadas de DMSO possivelmente provocaram toxicidade das células, conforme relatado por Gonzalez-Arnao et al. (2008), pois Hubálek (2003) descreveu que esse crioprotetor provoca alterações na membrana celular, as quais danificam e inviabilizam as células. Este efeito tóxico pode ser observado mesmo com o uso de concentrações muito baixas e é, em geral, potencializado quando o material biológico é exposto por longos períodos.
Diversos estudos têm relatado o efeito citotóxico do DMSO como crioprotetor. Ao criopreservarem sementes ortodoxas de alface, Kaurin \& Stushnoff (1985) constataram que a concentração do DMSO entre 5 e $15 \%$ é ideal para a criopreservação e acima desse valor as sementes perdem a capacidade germinativa. Sementes de espécies nativas da Austrália foram prejudicadas ao serem criopreservadas com 15 ou $35 \%$ de DMSO (Thouchell \& Dixon 1993). Resultados semelhantes foram obtidos na criopreservação de sementes hidratadas de alface, com DMSO a $35 \%$ (Jaganathan \& Liu 2014).

Ao contrário do DMSO, a sacarose provocou menor toxicidade nas sementes com a elevação da concentração, observada pelo melhor desempenho fisiológico das 
sementes de $P$. mucronata. Segundo Dumet et al. (1993), a sacarose constituí um ótimo agente crioprotetor e não apresenta citotoxidade, mesmo quando acumulada em grande quantidade no citoplasma. Santos (2000) afirma que sua utilização em concentrações elevadas diminui o conteúdo de água do ambiente celular, apresentando grande eficiência na estabilização das membranas celulares durante o congelamento, podendo agir como agente osmótico externo, removendo o excesso de água intracelular através de gradiente osmótico ou substituindo a água removida das biomoléculas, mantendo as estruturas hidrofílicas na sua orientação hidratada mesmo depois da remoção da água.

Koleva et al. (2012) avaliando o efeito dos crioprotetores sacarose e ABA na estrutura dos cloroplastos de plantas de Orthosiphon stamineus Benth., observaram que folhas tratadas com sacarose $(0.3 \mathrm{M})$, por 16 horas, mantiveram a organização histológica e o tecido fotossintético bem estruturado, semelhante aos das plantas cultivadas sem crioprotetor. Plantas cultivadas com $\mathrm{ABA}(0.076 \mu \mathrm{M}$ - por 10 dias) exibiram posição dos cloroplastos e estruturação dos tilacóides atípicos para a espécie. Os autores revelaram que o tratamento com sacarose assegura a estruturação regular do aparelho plastidial e, portanto, promove estabilidade na regeneração das plantas após a criopreservação.

Por outro lado, as sementes criopreservadas, sem o uso de crioprotetor, apresentaram percentual de sobrevivência de $95 \%$. Provavelmente, este alto percentual pode ser atribuído ao conteúdo de água das sementes de 7,5\%, considerado um valor seguro para criopreservação da espécie, conforme descrito no trabalho realizado por VeigaBarbosa et al. (2013). Araújo et al. (2016) trabalhando com sementes de maracujá com conteúdo de agua nas sementes iguais e inferiores a $12 \%$ também obtiveram sucesso na criopreservação das sementes sem o uso de crioprotetores. Segundo González-Benito et al. (2009), na criopreservação de sementes de Passiflora é importante que o conteúdo de água das sementes seja mantido entre um valor não muito alto para que não ocorra a formação de cristais de gelo ou muito baixo, o que pode induzir danos ao embrião pela dessecação.

O índice de velocidade de emergência (IVE; Fig. 1B) apresentou distribuição dos dados semelhante à emergência, ou seja, houve uma redução até a máxima concentração estudada, independente do tipo de crioprotetor avaliado. Mais uma vez, o DMSO provocou uma diminuição drástica nos valores de IVE (zero), mantendo-se sempre inferior a sacarose, que apesar do melhor desempenho $(2,92)$, demonstrou afetar negativamente o vigor das sementes à medida que a solução se tornou mais concentrada. Isso indica que as sementes apresentaram maior sensibilidade às concentrações dos crioprotetores, concordando com Gonzalez-Arnao et al. (2008).

Martínez-Montero et al. (2002) também relataram possíveis danos causados pela perda da integridade celular devido à formação de cristais de gelo e ao emprego do crioprotetor. Segundo Suzuki et al (2005) a ocorrência de danos ao tecido vegetal pela exposição a ultrabaixa temperatura depende da permeabilidade e da concentração do crioprotetor. No entanto, ainda não está claro como as soluções crioprotetoras agem para reduzir danos em tecidos e células durante o congelamento e descongelamento, nem se existem mecanismos comuns de crioproteção nas duas classes de compostos.

Para o comprimento da parte aérea (Fig. 1C) pode-se observar que os dados seguiram o modelo quadrático, em que as melhores concentrações calculadas foram de 2,3 e $17,6 \%$, respectivamente para o crioprotetor DMSO e sacarose, atingindo os comprimentos máximos respectivos de 6,6 e 7,5 cm. Entre as concentrações testadas, 14\% de DMSO e $21 \%$ de sacarose foram as que proporcionaram maior comprimento médio de parte aérea, correspondendo a 7,12 cm e 7,64 cm, respectivamente.

Conforme Souza et al. (2005) as sementes vigorosas originam plântulas com maior taxa de crescimento, em razão de apresentarem maior capacidade de translocação de suas reservas e maior assimilação destas pelo eixo embrionário. Desse modo, é possível inferir que sementes de $P$. mucronata tratadas com sacarose se mostraram mais vigorosas do que as tratadas com DMSO.

Analisando o comprimento médio das raízes (Fig. 1D), observa-se que nas plântulas provenientes das sementes tratadas com sacarose, não houve efeito das concentrações desse crioprotetor, sendo o valor médio de $3,10 \mathrm{~cm}$. Quando se utilizou o crioprotetor DMSO, houve ajuste de regressão quadrática, sendo a maior média estimada na concentração de $0,8 \%$, correspondendo a $3,10 \mathrm{~cm}$, decrescendo a partir desse ponto. Para esse crioprotetor, a concentração de 7\% apresentou maior média de comprimento de radícula, em comparação as demais testadas, correspondendo a $3,33 \mathrm{~cm}$.

$\mathrm{O}$ acúmulo de massa seca de plântulas (Fig. 1E) provenientes das sementes tratadas com sacarose apresentou valor médio de $0,15 \mathrm{~g}$ nas concentrações utilizadas, não tendo ocorrido ajustes significativos. Portanto, a massa seca dessas plântulas não foi afetada pelas concentrações de sacarose. Contudo, nas sementes tratadas com DMSO houve redução quadrática da massa seca, apresentando acúmulo nulo, com o aumento da concentração. Como essa redução também foi notada na emergência observase que a crioproteção das sementes nas concentrações de DMSO entre 14 e $28 \%$ afeta sua qualidade fisiológica. O crioprotetor sacarose se mostrou eficiente na crioproteção das sementes mais as sementes que não foram submetidas a nenhum tratamento crioprotetor também se mantiveram viáveis e com um alto vigor. Já o crioprotetor DMSO prejudicaram o potencial de emergência e o vigor das sementes em todas as concentrações utilizadas.

O tipo de crioprotetor e a aplicação de doses crescentes afetam a qualidade fisiológica de sementes de $P$. mucronata após o armazenamento em nitrogênio líquido. E, as sementes podem ser armazenadas em nitrogênio líquido sem o uso de crioprotetores. 


\section{AGRADECIMENTOS}

Ao Conselho Nacional de Desenvolvimento Científico e Tecnológico (CNPq), pelo financiamento da pesquisa.

\section{REFERÊNCIAS}

Araújo, D.S., Luz, P.B., Neves, L.G., \& Paiva Sobrinho, S. 2016. Seed cryopreservation of Passiflora species. Journal of Seed Science 38 (3): 248-253

Brasil. Ministério da Agricultura, Pecuária e Abastecimento 2009. Regras para análise de sementes. Ministério da Agricultura, Pecuária e Abastecimento, Brasília. 395p.

Cervi, A.C. 1997. Passifloraceae do Brasil: estudo do gênero Passiflora L., subgênero Passiflora. Fontqueria 45(1):1-92.

Cromarty, A.S., Ellis, R.H. \& Roberts, E.H. 1985. Design of seed storage facilities for genetic conservation. International Board for Plant Genetic Resources, Rome. 100p.

Cruz, T.V., Souza, M.M., Roza, F.A., Viana, A.J.C., Belo, G.O. \& Fonseca, J.W.S. 2008. Germinação in vitro de grãos de pólen em Passiflora suberosa L. para sua utilização em hibridação interespecífica. Revista Brasileira de Fruticultura 30(4):875-879.

Dumet, D., Engelmann, F., Chabrillange, N., Duval, Y. \& Dereuddre, J. 1993. Importance of sucrose for the acquisition of tolerance to desiccation and cryopreservation of oil palm somatic embryos. Cryoletters 14(1):243-250.

Engelmann, F. 2011. Use of biotechnologies for the conservation of plant biodiversity. In Vitro Cellular \& Developmental BiologyPlant 47(1):5-16.

Ferreira, D.F. 2010. Sisvar: a computer Statistical analysis system. Versão 5.3. Universidade Federal de Lavras, Departamento de Ciências Exatas, Lavras.

Gonzalez-Arnao, M.T., Panta, A., Roca, W.M., Escobar, R.H. \& Engelmann, F. 2008. Development and large scale application of cryopreservation techniques for shoot and somatic embryo cultures of tropical crops. Plant Cell Tissue and Organ Culture. 92(1):1-13.

González-Benito, M.E., Aguilar, N. \& Ávila, T. 2009. Germination and embryo rescue from Passiflora species seeds post-cryopreservation. Cryoletters 30(2):142-147.

Hubálek, Z. 2003. Protectants used in the cryopreservation of microorganisms. Cryobiology 46(3) 205-229.
Jaganathan, G.K. \& Liu, B. 2014. Effects of dimethyl sulfoxide concentration, pre-cooling and cooling rate on cryopreservation of hydrated lettuce seeds. Seed Science and Technology 42(3):214-226.

Kaurin, A. \& Stushnoff, C. 1985. Influence of dimethyl sulfoxide on freezing resistance of lettuce seeds. Cryobiology 22:569-573.

Koleva, D.P., Ganeva, T.G. \& Stefanova, M.A. 2012. Effect of cryoprotectants sucrose and ABA on chloroplasts structure in regenerated after cryopreservation Orthosiphon stamineus Benth. Plants. Journal of Pharmacy Research 5(8):4172-4174.

Maguire, J. D. 1962. Speed of germination aid in selection and evaluation for seedling emergence and vigor. Crop Science 2(2):176-177.

Martínez-Montero, M.E., Mora, N., Quiñones, J., González-Arnao, M.T., Engelmann, F. \& Lorenzo, J.C. 2002. Effect of cryopreservation on the structural and functional integrity of cell membranes of sugarcane (Saccharum sp.) embryogenic calluses. Cryoletters 23(4)237-244.

Meletti, L.M.M., Soares-Scott, M D., Bernacci, L.C., Alvares, V. \& Azevedo Filho, J.A. 2011. Caracterização de Passiflora mucronata Lam.: nova alternativa de maracujá ornamental. Revista Brasileira de Horticultura Ornamental 17(1):87-95.

Santos, I.R.I. 2000. Crioconservação: potencial e perspectivas para a conservação de germoplasma vegetal. Revista Brasileira de Fisiologia Vegetal 12:70-84.

Santos, T.M., Flores, P.S., Oliveira, S.P., Silva, D.F.P. \& Bruckner, C.H. 2012. Tempo de armazenamento e método de quebra de dormência em sementes do maracujá-de-restinga. Revista Brasileira de Agropecuária Sustentável 2(1):26-31.

Sakai, A. \& Engelmann, F. 2007. Vitrification, encapsulation-vitrification and droplet-vitrification: a review. Cryoletters 28(3):151-172.

Souza, V.C., Bruno, R.L.A. \& Andrade, L.A. 2005. Vigor de sementes armazenadas de ipê-amarelo Tabebuia serratifolia (Vahl.) Nich. Revista Árvore 29(6):833-841.

Suzuki, A.B.P., Junior Bertoncelli, D., Alves, G.A.C., \& de Faria, R.T. 2018. Criopreservação de sementes da orquídea brasileira em extinção Cattleya granulosa Lindl. Iheringia, Série Botânica 73(2):146-150.

Suzuki, T., Kami, D., Oosawa, K. \& McGann, L.E. 2005. Cryoprotection in plant tissues related to reduced volume expansion of cryoprotectant solution. Cryoletters 26(3):159-168.

Touchell, D.H. \& Dixon, K.W. 1993. Cryopreservation of seed of Western Australian native species. Biodiversity and Conservation 2(6):594602.

Veiga-Barbosa, L., Mira, S., González-Benito, M.E., Souza, M. M., Meletti, L.M.M. \& Pérez-García, F. 2013. Seed germination, desiccation tolerance and cryopreservation of Passiflora species. Seed Science \& Technology 41:89-97 